Int. J. Odontostomat., 10(1):99-106, 2016.

\title{
Oral Lichen Planus: Clinical Profile and Determination of Oral Epithelial Dysplasia
}

\author{
Liquen Plano Oral: Perfil Clínico y Determinación de la Displasia Epitelial Oral
}

\begin{abstract}
Seani Neumann Paiva*; Cláudia Cristina Braga*; Karla Loureiro Almeida-Coburn*; Willian Grassi Bautz ${ }^{\star * *}$; Liliana Aparecida Pimenta de Barros ${ }^{\star * * *}$ \& Letícia Nogueira da Gama-de-Souza**
\end{abstract}

PAIVA, S. N.; BRAGA, C. C.; ALMEIDA-COBURN, K. L.; BAUTZ, W. G.; DE BARROS, L. A. P. \& DA GAMA-DE-SOUZA, L. N. Oral lichen planus: clinical profile and determination of oral epithelial dysplasia. Int. J. Odontostomat., 10(1):99-106, 2016.

ABSTRACT: Oral lichen planus (OLP) is the most common noninfectious oral disease and is considered a potentially malignant disorders (OPMDs). The etiology and pathogenesis of OLP are not completely understood and the malignant transformation remains under discussion. The aim was to asses the cytological and histological features of OLP, and establish relationship between clinical and microscopic profiles. A total of 10 patients diagnosed with OLP were investigated. Slides were prepared and stained with Hematoxylin-Eosin to identify 8 histological features and 8 cytological alterations. Finally, oral epithelial dysplasia degree was determined. Hyperplasia and loss of polarity of basal cells were detected in $90 \%$ of cases. Anisonucleosis, nuclear pleomorphism and hyperchromasia affected $100 \%$ of the sample. Six cases were classified as mild-grade OED, with no cases of severe-grade. Microscopic alterations were higher in women $(P<0.0001)$ and moderategrade OED was diagnosed only in this group $(P<0.0014)$. The findings demonstrated that microscopic and clinical data association should be analyzed to a better understand of disease behavior. OED was absence only in one case, so the periodic follow-up of patients diagnosed with OLP is mandatory to avoid the malignant transformation.

KEY WORDS: oral epithelial dysplasia, oral lichen planus, potentially malignant disorders.

\section{INTRODUCTION}

The lesions or conditions of oral cavity with potential malignancy were defined as "potentially malignant disorders" (OPMDs) in a workshop coordinated by World Health Organization (Barnes et al., 2005). It is well accepted that OPMDs could precede oral squamous cell carcinoma (OSCC) (Warnakulasuriya et al., 2007). In a wide range of different OPMDs, lichen planus (OLP) is an autoimmune chronic disease mediated by $T$ lymphocytes that involves the stratified squamous epithelial tissue which etiology and pathogenesis is not completely understood. It's the most common noninfectious oral disease, often detected in mucosa, tongue and gum, and is estimated to affect $0.5 \%$ to
$2.0 \%$ of general population (Ismail et al., 2007; Roopashree et al., 2010; Gupta \& Jawanda, 2015).

The age ranges from 30-60 years, and is more common in women (Wang et al., 2015). Unlike OSCC, risk factors implicated as potential initiators and/or promoters include tobacco, alcohol, ultraviolet radiation, human papillomavirus (HPV), immunosuppression, areca nut (betel nut or quid), and socioeconomic status are not directly linked to OLP development (Huber \& Tantiwongkosi, 2014). On the other hand, there is growing interest in non-smoking non-drinking (NSND) patients presenting with OSCC. Koo et al. (2013) identified a distinct subgroup of elderly

School of Dentistry, Health Science Center, University of Espírito Santo, Vitória, Brazil.

" Postgraduate Program in Dental Clinic, Department of Morphology, Health Science Center, University of Espírito Santo, Vitória, Brazil.

${ }^{* * *}$ Department of Morphology, Health Science Center, University of Espírito Santo, Vitória, Brazil. University of São Paulo, Faculty of Medicine, São Paulo, Brazil.

**** Department of Dental Clinic, Health Science Center, University of Espírito Santo, Vitória, Brazil.

Funding sources that supported this work: This work was supported by grants from Brazilian National Council for Scientific and Technological Development (CNPq) process number: 479694 2013-3 and the State of Espírito Santo Research Foundation (FAPES) 006/2014 process number: 67659870. 
female patients presenting with OSCC not associated with the traditional risk factors, who have a worse prognosis. There are, however, few published reports of OSCC in the elderly.

Although OLP demonstrated benign behavior, the malignant transformation remains under discussion. According to van der Meij et al. (1999) there is a tendency to accept its potential transformation, with a rate amounting less than $0.5 \%$. In a systematic review, Fitzpatrick et al. (2014) evaluated evidence of malignant transformation, and in a total of 7,806 patients with OLP, 85 developed OSCC, which represents 1.09 percent of transformation rate. Other reports also associated OLP with oral cancer (Roopashree et al.; Gorsky \& Epstein, 2011). It is widely accepted that early diagnosis and treatment of OPMDs are relevant to prevent OSCC. In the last years, diagnosis has been based mainly on clinical and histological data. Therefore, a detailed microscopic analysis of those lesions is critical for a better understanding of distinct clinical behavior and evolution. In this context, the detection and degree determination of epithelial dysplasia represent an important feature that could lead to a more accurate diagnosis of OPMDs, such as OLP.

Essentially, oral epithelial dysplasia (OED) has been considered the most important microscopic aspect of those disorders and it is defined by the presence of specifics histological and cytological alterations. Oral pathologists need to detect a combination of architectural changes in epithelium before grading dysplasia (Warnakulasuriya et al., 2008; Pitiyage et al., 2009; Liu et al., 2011). However, defining OED degree and malignancy transformation is still a challenge. Diagnosis of individual features of epithelial dysplasia is required to design systems of high predictive value, especially in the upper aerodigestive tract, where there is considerable variation in epithelial structure (Tilakaratne et al., 2011).

The purpose of this study was to identify the histological and cytological alterations of epithelial dysplasia in OLP cases and define OED degree. The correlation between microscopic findings with clinical data was also performed.

\section{MATERIAL AND METHOD}

Study population. The retrospective study was approved by Ethics Committee of the Institution where it was developed (protocol 071/10- Federal University of Espírito Santo/UFES, Brazil). Written informed consent was obtained from each participant and the study was performed in accordance with the Declaration of Helsinki. Paraffin-embedded tissue samples of OLP were obtained by biopsies from different sites of oral mucosa from the archives of the Oral Pathology Laboratory of Dentistry School/UFES between 2004-2010. Clinical and histopathological data were collected from medical records and included: gender, age, lesion site and history of tobacco exposure. Exclusion criteria were: incomplete clinical data and insufficient sample for microscopic analysis.

Microscopic analysis. Slides of OLP samples were prepared and stained with Hematoxylin-Eosin (HE) to identify histological and cytological alterations and to define OED degree. The criteria applied for diagnosis are consistent with Warnakulasuriya et al. The histological features studied were: irregular epithelial stratification, loss of polarity of basal cells, basal cells hyperplasia, drop-shaped rete ridges, increased number of mitotic figures, abnormally superficial mitoses, dyskeratosis and keratin pearls. The cytological feature variables considered were: anisonucleosis, nuclear pleomorphism, cellular pleomorphism, increased in nuclear-cytoplasmic ratio, increased nuclear size, increased number and size of nucleoli, hyperchromasia and atypical mitotic figures. Each feature was classified as present or absent. After that, lesions were scored for epithelial dysplasia degree as mild, moderate or severe-grade. Images were acquired with a light microscope (Primo Star, Zeiss, Germany) coupled to a digital camera system (Axiocam HRP, Zeiss, Germany) at 100X magnification

Statistical Analysis. Statistical analysis was performed using the GraphPad Prism 5.01 program (GraphPad Software, Inc., San Diego, CA, USA). Association between clinical data with microscopic features was tested by Two-way ANOVA. The results were considered significant when $p<0.05$.

\section{RESULTS}

Clinical data: From the 797 oral and maxillofacial lesions retrieved from the files of Oral Pathology Laboratory, 13 cases were diagnosed as OLP. Of these total cases, 3 were excluded due to incomplete clinical data and/or insufficient sample for microscopic analysis. OLP lesions represented $1.63 \%$ of oral diseases 
diagnosed in the Oral Pathology Service (UFES, Brazil). Age range 26-94 years (median, 47.5 years) and most of patients were older than 40 years $(60 \%)$, women $(80 \%)$ and the most affected site was jugal mucosa (60\%). Regarding habits, $60 \%$ of patients related no smoking. Table I summarized patient data.

Microscopic findings: Regarding histological features, hyperplasia and loss of polarity of basal cells were the most common (90\%). Anisonucleosis, nuclear pleomorphism and hyperchromasia represented the cytological variables that affected $100 \%$ of the cases (Table II). After microscopic variables identification, the OED was determined and $60 \%$ of lesions were classified as mild-grade with no cases of severe-grade (Table I). The clinical and histopathological features are presented in Figure 1.
Presence of OLP with mild-grade $(A)$ and moderategrade (B) dysplasia in jugal mucosa. Loss of polarity of basal cells, anisonucleosis and nuclear pleomorphism is observed in mild-grade lesion (C), on other hand, irregular epithelial stratification, loss of polarity of basal cells, anisonucleosis, nuclear and cellular pleomorphism could be detected in moderategrade lesion (D).

Association of clinical and microscopic data: Some epithelial dysplasia variables were tested to identify possible associations between microscopic features and gender. It was possible to observe that histological and cytological alterations were found in a higher frequency in female patients $(P<0.0001)$ (Fig. 1E). Still, OLP with moderate-grade epithelial dysplasia was diagnosed only in women ( $P<0.0014)$ (Fig. 1F).

Table I. Data from patient's included in this study.

\begin{tabular}{lccccc}
\hline Patie nt & Sex & Age & Site & Smoking & OED \\
\hline 1 & $\mathrm{~F}$ & 29 & Jugal mucosa & $\mathrm{N}$ & Mild \\
2 & $\mathrm{M}$ & 26 & Jugal mucosa & $\mathrm{NI}$ & Mild \\
3 & $\mathrm{~F}$ & 57 & Jugal mucosa & $\mathrm{N}$ & Absence \\
4 & $\mathrm{M}$ & 50 & Gum & $\mathrm{N}$ & Mild \\
5 & $\mathrm{~F}$ & 53 & Gum & $\mathrm{NI}$ & Mild \\
6 & $\mathrm{~F}$ & 39 & Jugal mucosa & $\mathrm{N}$ & Mild \\
7 & $\mathrm{~F}$ & 22 & Jugal mucosa & $\mathrm{N}$ & Mild \\
8 & $\mathrm{~F}$ & 94 & Gum & $\mathrm{NI}$ & Mild \\
9 & $\mathrm{~F}$ & 56 & Jugal mucosa & $\mathrm{Y}$ & Moderate \\
10 & $\mathrm{~F}$ & 49 & Tongue & $\mathrm{N}$ & Moderate \\
\hline $\mathrm{N}=$ No; Y= Yes; NI= No Informed; OED= oral epithelial dysplasia; F= female and \\
$\mathrm{M}=$ male.
\end{tabular}

Table II. Frequency of histological and citological variables of OLP cases.

\begin{tabular}{llc}
\hline & & $\mathbf{n ~ ( \% )}$ \\
\hline Histological & Irregular epithelial stratification & $2(20 \%)$ \\
variable & Loss of polarity of basal cells & $9(90 \%)$ \\
& Basal cells hyperplasia & $9(90 \%)$ \\
& Gout formations & $3(30 \%)$ \\
& Increased number of mitotic figures & $2(20 \%)$ \\
& Abnormally superficial mitoses & $1(10 \%)$ \\
& Dyskeratosis & $1(10 \%)$ \\
Citological & Keratin pearls & 0 \\
variable & Abnormal variation in nuclear size (anisonucleosis) & $10(100 \%)$ \\
& Nuclear pleomorphism & $10(100 \%)$ \\
& Cellular pleomorphism & $8(80 \%)$ \\
& Increased nuclear-cytoplasmic ratio & $5(50 \%)$ \\
& Increased nuclear size & $5(50 \%)$ \\
& Increased number-size of nucleoli & $7(70 \%)$ \\
& Hyperchromasia & $10(100 \%)$ \\
& Atypical mitotic figures & $6(60 \%)$ \\
\hline
\end{tabular}



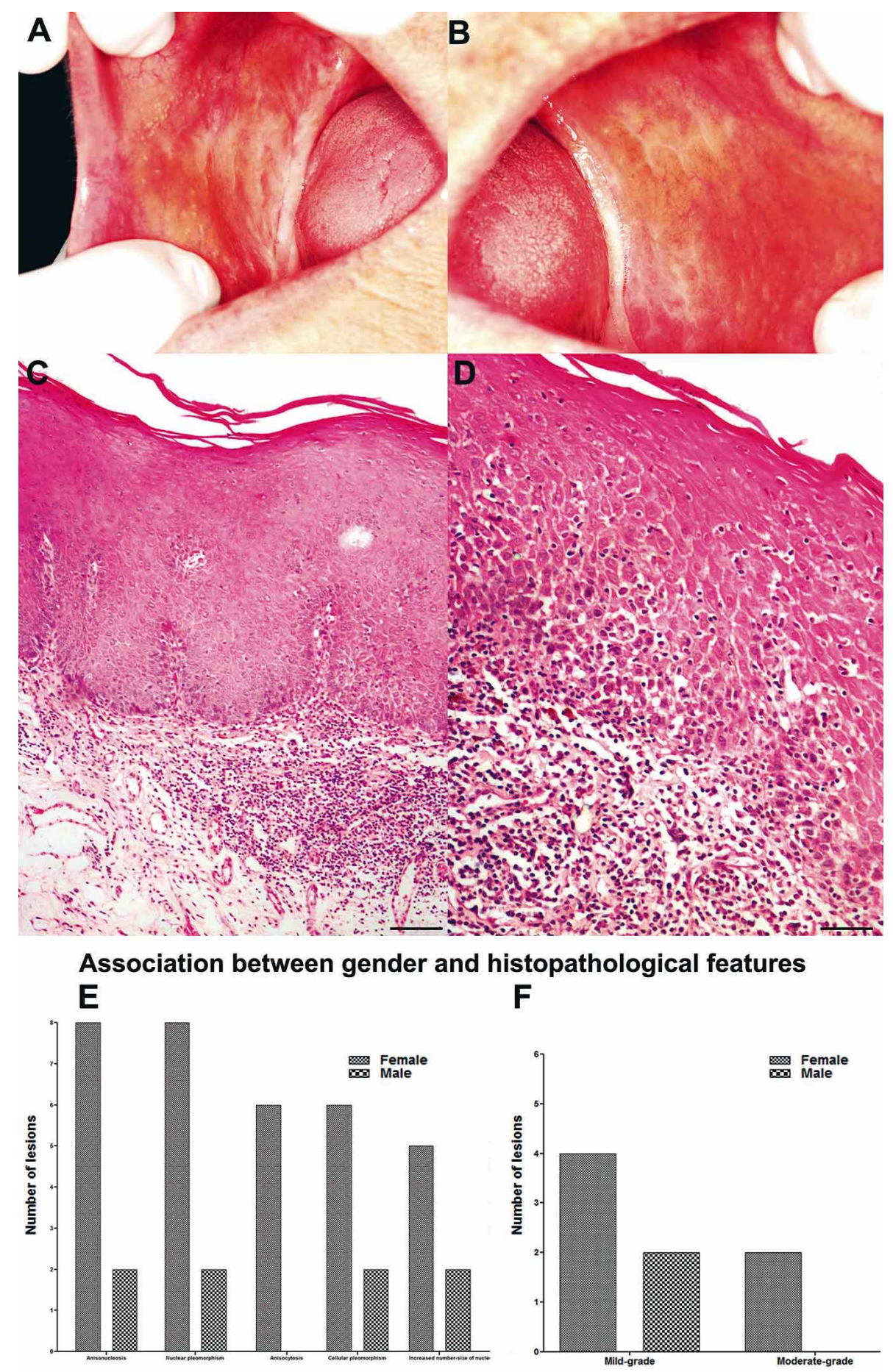

Fig. 1. Clinical and histopathological features of OLP. (A and B) OLP in bilateral jugal mucosa. (C) Loss of polarity of basal cells, anisonucleosis and nuclear pleomorphism in mild-grade OLP. (D) Irregular epithelial stratification, loss of polarity of basal cells, anisonucleosis, nuclear and cellular pleomorphism in moderate-grade OLP. In both cases a rich inflammatory infiltrate is observed. H\&E, Scale bar $=50 \mu \mathrm{m}$. Graphs of association between smoking and microscopic data. (E) Appearance of anisonucleosis, nuclear and cellular pleomorphism, anisocytosis, and increased number-size of nucleoli were positive associated with female patients $(P<0.0001)$. $(F)$ The same was observed to OED degree $(\mathrm{P}<0.0014)$. 


\section{DISCUSSION}

Early diagnosis and treatment of OPMDs is essential to prevent the development of cancer. For a better understanding of malignant transformation, the association between clinical and histological features could be a determination to achieve a more accurate prognosis. In this context, epithelial dysplasia represents an important aspect in OPMDs diagnosis. Besides, the OED grade is considered crucial (Shailaja et al., 2015), there is a lack of universally accepted guidelines for treatment of those lesions (Balasundaram et al., 2014).

OLP represented $1.63 \%$ of lesions diagnosed in Oral Pathology Service between 2004-2010, a percentage compatible with literature, that estimated $0.5 \%$ to $2.0 \%$ (Ismail et al.; Roopashree et al.; Gupta \& Jawanda). The clinical findings showed that women were the most affected gender, which is in agreement with other reports (Roopashree et al.; Wang et al.; Coelho et al., 2000; Corrêa et al., 2006; Carvalho et al., 2011). Regarding age, patients older than 40 years were the major group, consistent with Carvalho et al. The main affected site was jugal mucosa, as mentioned by others studies in Brazil and different countries (Fernández-González et al., 2010; Oliveira Alves et al., 2010; Werneck et al., 2015).

When frequency of histological and cytological feature was analyzed, some dysplastic variables were presented in a higher frequency, such as, hyperplasia and loss of polarity of basal cells, anisonucleosis, nuclear pleomorphism and hyperchromasia. Tilakaratne et al. analyzed the individual features of epithelial dysplasia in 86 oral lesions and determined the reproducibility of scoring for each. The authors emphasized that some microscopic findings presented a wide variation in the scoring, including anisonucleosis, basal dyscohesion and dyskeratosis. Despite this, it is important to emphasize that OED degree determination of OPMDs is crucial as an indicator of malignant transformation risk. We detected $60 \%$ of OLP with mildgrade and $30 \%$ as moderate-grade. Any case was diagnosed as severe-grade. Wei Liu et al. demonstrated that patients diagnosed with severegrade dysplasia had a higher oral cancer incidence than those with mild-grade. Whereas the cutaneous lichen planus is described with no risk of malignant transformation (Sigurgeirsson \& Lindelöf, 1999; Ramos-e-Silva et al., 2010), the oral forms had been documented as a potentially lesion for cancer, with rates reaching $5.8 \%$ (Wei et al.; Ramos-e-Silva et al.; Rajentheran et al., 1999). Other rates of malignant transformation were reported, amounting to less than $0.5 \%$ (Warnakulasuriya et al.).

The microscopic criteria for OLP and its epithelial dysplasia diagnosis represent a challenge and are controversial. However, is important to considered that epithelium in this kind of disease may develop dysplasia during carcinomatous transformation process (Gonzalez-Moles et al., 2008). When OED is presented, some authors classified the lesion as lichenoid dysplasia (LD) (Van der Meij et al., 2003). Lodi et al. (2014) distinguished LD in 2 groups of conditions: those with clinical features similar to OLP but with dysplasia; and those with lichenoid microscopic features (bandlike lymphocytic infiltration in particular) and clinical aspect which do not resemble classic OLP (unilateral distribution absence of reticular lesions). The first one could be an early phase in OLP malignant transformation, while the latter could represent various clinical conditions including lichenoid reactions, lupus erythematosus, leukoplakia, erythroleukoplakia, and proliferative verrucous leukoplakia (PVL). The importance of dysplasia presence or absence diagnosis is clear, and when the presence is confirmed, the determination degree might be procedure, even for lesions considered benign with low potential malignancy transformation (Pereira et al., 2011). In Oral Pathology Service (UFES, Brazil) since 2011, in most cases of OLP there has been a biopsy to identify and document a possible OED, and the follow-up of those patients became more frequent.

A large number of studies connected lifestyle habits with transformation of OPMDs into cancer, especially smoking, known as the most important factor (Wei et al.; Pereira et al.; Goodson et al., 2010). Although habits are not considered independent risk factors and their roles in malignant transformation are conflicting, the identification is important since treatment could be compromised. Many studies reviewed case reports of cancer in patients affected by OLP, however, most of that was rejected due to lack of criteria (Lodi et al.). The Krutchokoff's criteria adopted by scientific literature in cases of OLP, tobacco exposure might be properly documented to help distinguish between a true malignant transformations and conventional carcinomas (Van der Meij et al., 1999). In our sample, only one related smoking habit. OLP is an autoimmune disease with inflammatory feature and the presence of microscopic alterations may be the result of inflammation more than habit 
(Sousa \& Rosa, 2008). Futhermore, the identification of a distinct clinical subgroup of NSND patients with OSCC and different demographic distribution it must be analyzed. Absence of risk factors and female gender are important features of OLP, predominant profile found in our cases, in agreement with other reports (Wang et al.; Werneck et al.). When the association of dysplastic cell factors and clinical data was analyzed, the presence of anisonucleosis, nuclear and cellular pleomorphism, anisocytosis, and increased numbersize of nucleoli were influenced by gender, as well as the OED degree. A lack of clinicopathological correlation in the diagnosis leads towards the need for more investigation to clarify the malignant transformation of OLP.

The gold standard for the assessment of those lesions remains the microscopic evaluation of $\mathrm{HE}$ slides. The microscopic profile is only possible through the identification of OLP and performing the biopsy, which has been recommended in many services of oral diagnosis, as well as in our service.

The findings demonstrated that microscopic and clinical data association should be analyzed to a better understand of disease profile and behavior. The patients of our study sample showed similar features of other reports and OED was absent in only one case. So the periodic follow-up is mandatory for early detection of oral cancer.

\section{ACKNOWLEDGEMENTS}

The authors gratefully acknowledge the LUCCAR Laboratory, Morphology Department, Federal University of Espírito Santo, Brazil.

PAIVA, S. N.; BRAGA, C. C.; ALMEIDA-COBURN, K. L.; BAUTZ, W. G.; DE BARROS, L. A. P. \& DA GAMA-DE-SOUZA, L. N. Liquen plano oral: perfil clínico y la determinación de la displasia epitelial oral. Int. J. Odontostomat., 10(1):99-106, 2016.

RESUMEN: El liquen plano oral (LPO) es la enfermedad no infecciosa más común y se considera un trastorno potencialmente maligno. La etiología y la patogénesis del LPO no se conoce y la transformación maligna sigue siendo objeto de debate. El objetivo de este estudio fue evaluar las características citológicas e histológicas del LPO y establecer la relación entre los perfiles clínicos y microscópicos. Un total de 10 pacientes diagnosticados con LPO fueron investigados. Secciones histológicas se prepararon y tiñeron con hematoxilina-eosina para identificar 8 características histológicas y 8 alteraciones citológicas. Finalmente, se determinó el grado de displasia epitelial. La hiperplasia y la pérdida de la polaridad de las células basales se detectaron en el $90 \%$ de los casos. Anisonucleosis, pleomorfismo nuclear e hipercromasia afectaron al $100 \%$ de las muestras. Seis casos fueron clasificados como displasia epitelial oral (DEO) de grado leve y no se reportaron casos de grado severo. Las alteraciones microscópicas fueron mayores en las mujeres $(p<0,0001)$ y DEO de grado moderado fue diagnosticado sólo en este grupo $(p<0,0014)$. Los resultados demostraron que la asociación de datos microscópicos y clínicos deben ser analizados para una mejor comprensión del comportamiento de la enfermedad. La DEO estuvo ausente sólo en un caso, por lo que el seguimiento periódico de los pacientes diagnosticados con LPO es necesario para evitar la transformación maligna.

PALABRAS CLAVE: displasia epitelial oral, liquen plano oral, trastornos potencialmente malignos.

\section{REFERENCES}

Balasundaram, I.; Payne, K. F.; Al-Hadad, I.; Alibhai, M.; Thomas, S. \& Bhandari, R. Is there any benefit in surgery for potentially malignant disorders of the oral cavity? J. Oral Pathol. Med., 43(4):239-44, 2014.

Barnes, L.; Eveson, J.W.; Reichart, P. \& Sidransky, D. Pathology and Genetics of Head and Neck Tumours. In: Kleihues, P. \& Sobin, L. H. (Eds.). World Health Organization Classification of Tumours. Lyon, International Agency for Research on Cancer Press, 2005.
Carvalho, Mde. V.; Iglesias, D. P.; do Nascimento, G. J. \& Sobral, A. P. Epidemiological study of 534 biopsies of oral mucosal lesions in elderly Brazilian patients. Gerodontology, 28(2):111-5, 2011.

Coelho, C. M.; Zucoloto, S. \& Lopes, R. A. Denture-induced fibrous inflammatory hyperplasia: a retrospective study in a school of dentistry. Int. J. Prosthodont., 13(2):148$51,2000$.

Corrêa, L.; Frigerio, M. L.; Sousa, S. C. \& Novelli, M. D. Oral lesions in elderly population: a biopsy survey using 2250 histopathological records. Gerodontology, 23(1):48-54, 2006. 
Fernández-González, F.; Vázquez-Álvarez, R.; ReboirasLópez, D.; Gándara-Vila, P.; García-García, A. \& Gándara-Rey, J. M. Histopathological findings in oral lichen planus and their correlation with the clinical manifestations. Med. Oral Patol. Oral Cir. Bucal, 16(5):e641-6, 2011.

Fitzpatrick, S. G.; Hirsch, S. A. \& Gordon, S. C. The malignant transformation of oral lichen planus and oral lichenoid lesions: a systematic review. J. Am. Dent. Assoc., 145(1):45-56, 2014.

Gonzalez-Moles, M. A.; Scully, C. \& Gil-Montoya, J. A. Oral lichen planus: controversies surrounding malignant transformation. Oral Dis., 14(3):229-43, 2008.

Goodson, M. L.; Hamadah, O. \& Thomson, P. J. The role of alcohol in oral precancer: observations from a NorthEast England population. Br. J. Oral Maxillofac. Surg., 48(7):507-10, 2010.

Gorsky, M. \& Epstein, J. B. Oral lichen planus: malignant transformation and human papilloma virus: a review of potential clinical implications. Oral Surg. Oral Med. Oral Pathol. Oral Radiol. Endod., 111(4):461-4, 2011.

Gupta, S. \& Jawanda, M. K. Oral lichen planus: An update on etiology, pathogenesis, clinical presentation, diagnosis and management. Indian J. Dermatol., 60(3):222-9, 2015.

Huber, M. A. \& Tantiwongkosi, B. Oral and oropharyngeal cancer. Med. Clin. North Am., 98(6):1299-321, 2014.

Ismail, S. B.; Kumar, S. K. \& Zain, R. B. Oral lichen planus and lichenoid reactions: etiopathogenesis, diagnosis, management and malignant transformation. J. Oral Sci., 49(2):89-106, 2007.

Koo, K.; Barrowman, R.; McCullough, M.; Iseli, T. \& Wiesenfeld, D. Non-smoking non-drinking elderly females: a clinically distinct subgroup of oral squamous cell carcinoma patients. Int. J. Oral Maxillofac. Surg., 42(8):929-33, 2013.

Liu, W.; Bao, Z. X.; Shi, L. J.; Tang, G. Y. \& Zhou, Z. T. Malignant transformation of oral epithelial dysplasia: clinicopathological risk factors and outcome analysis in a retrospective cohort of 138 cases. Histopathology, 59(4):733-40, 2011.

Lodi, G.; Scully, C.; Carrozzo, M.; Griffiths, M.; Sugerman, P. B. \& Thongprasom, K. Current controversies in oral lichen planus: report of an international consensus meeting. Part 2. Clinical management and malignant transformation. Oral Surg. Oral Med. Oral Pathol. Oral Radiol. Endod., 100(2):164-78, 2005.
Oliveira Alves, M. G.; Almeida, J. D.; Balducci, I. \& Guimarães Cabral, L. A. Oral lichen planus: A retrospective study of 110 Brazilian patients. B. M. C. Res. Notes, 3:157, 2010.

Pereira, Jdos. S.; Carvalho, Mde. V.; Henriques, A. C.; de Queiroz Camara, T. H.; Miguel, M. C. \& Freitas, Rde. A. Epidemiology and correlation of the clinicopathological features in oral epithelial dysplasia: analysis of $173 \mathrm{ca}-$ ses. Ann. Diagn. Pathol., 15(2):98-102, 2011.

Pitiyage, G.; Tilakaratne, W. M.; Tavassoli, M. \& Warnakulasuriya, S. Molecular markers in oral epithelial dysplasia: review. J. Oral Pathol. Med., 38(10):737-52, 2009.

Rajentheran, R.; McLean, N. R.; Kelly, C. G.; Reed, M. F. \& Nolan, A. Malignant transformation of oral lichen planus. Eur. J. Surg. Oncol., 25(5):520-3, 1999.

Ramos-e-Silva, M.; Jacques, Cd. \& Carneiro, S. C. Premalignant nature of oral and vulval lichen planus: facts and controversies. Clin. Dermatol., 28(5):563-7, 2010.

Roopashree, M. R.; Gondhalekar, R. V.; Shashikanth, M. C.; George, J.; Thippeswamy S. H. \& Shukla, A. J. Pathogenesis of oral lichen planus--a review. J. Oral Pathol. Med., 39(10):729-34, 2010.

Shailaja, G.; Kumar, J. V.; Baghirath, P. V.; Kumar, U.; Ashalata, G. \& Krishna, A. B. Estimation of malignant transformation rate in cases of oral epithelial dysplasia and lichen planus using immunohistochemical expression of Ki-67, p53, BCL-2, and BAX markers. Dent. Res. J. (Isfahan), 12(3):235-42, 2015.

Sigurgeirsson, B. \& Lindelöf, B. Lichen planus and malignancy. An epidemiologic study of 2071 patients and a review of the literature. Arch. Dermatol., 127(11):16848, 1991.

Sousa, F. A. \& Rosa, L. E. Oral lichen planus: clinical and histopathological considerations. Braz. J. Otorhinolaryngol., 74(2):284-92, 2008.

Tilakaratne, W. M.; Sherriff, M.; Morgan, P. R. \& Odell, E. W. Grading oral epithelial dysplasia: analysis of individual features. J. Oral Pathol. Med., 40(7):533-40, 2011.

van der Meij, E. H.; Schepman, K. P.; Smeele, L. E.; van der Waal, J. E.; Bezemer, P. D. \& van der Waal, I. A review of the recent literature regarding malignant transformation of oral lichen planus. Oral Surg. Oral Med. Oral Pathol. Oral Radiol. Endod., 88(3):307-10, 1999.

van der Meij, E. H.; Schepman, K. P. \& van der Waal, I. The possible premalignant character of oral lichen planus and oral lichenoid lesions: a prospective study. Oral Surg. Oral Med. Oral Pathol. Oral Radiol. Endod., 96(2):16471, 2003. 
PAIVA, S. N.; BRAGA, C. C.; ALMEIDA-COBURN, K. L.; BAUTZ, W. G.; DE BARROS, L. A. P. \& DA GAMA-DE-SOUZA, L. N. Oral lichen planus: clinical profile and determination of oral epithelial dysplasia. Int. J. Odontostomat., 10(1):99-106, 2016.

Wang, Y.; Zhou, J.; Fu, S.; Wang, C. \& Zhou, B. A study of association between oral lichen planus and immune balance of Th1/Th2 cells. Inflammation, 38(5):1874-9, 2015.

Warnakulasuriya, S.; Johnson, N. W. \& van der Waal, I. Nomenclature and classification of potentially malignant disorders of the oral mucosa. J. Oral Pathol. Med., 36(10):575-80, 2007.

Warnakulasuriya, S.; Reibel, J.; Bouquot, J. \& Dabelsteen, E. Oral epithelial dysplasia classification systems: predictive value, utility, weaknesses and scope for improvement. J. Oral Pathol. Med., 37(3):127-33, 2008.

Werneck, J. T.; Costa, Tde. O.; Stibich, C. A.; Leite, C. A.; Dias, E. P. \& Silva Junior, A. Oral lichen planus: study of 21 cases. An. Bras. Dermatol., 90(3):321-6, 2015.
Correspondence to:

Letícia Nogueira da Gama de Souza

Postgraduate Program in Dental Clinic

Department of Morphology

Federal University of Espírito Santo

Marechal Campos av., 1468

Maruípe, Zip Code: 29.040-090

Vitória, ES

BRAZIL

Email: leticia.souza@ufes.br

Received: $10-12-2015$

Accepted: 11-03-2016 